\title{
Large Superconducting Radio Frequency Construction Projects
}

\author{
Claus H. Rode
}

\begin{abstract}
The SRF achievements of the last two decades will be reviewed; concentrating on the CEBAF, LEP, and SNS projects. The near term new SRF initiatives will also be presented.
\end{abstract}

Index Terms-Superconducting, CEBAF, LEP, SNS

\section{INTRODUCTION} HIS paper will cover the major SRF projects using elliptical cell cavities. It will not try to cover the many projects using low and medium velocity structures (Beta $<0.5)$.

Pre 1989 there had been four significant worldwide efforts:

- HEPL in the early 1970's

- Cornell cavity beam test in 1984, five-cell 1500 $\mathrm{MHz}$

- HERA 16 cavities, five-cell $500 \mathrm{MHz}$

- KEK 32 cavities, five-cell $508 \mathrm{MHz}$

This was followed by two major construction projects: CEBAF at Jefferson Lab and LEP II at CERN. Fig. 1 shows the growth of accelerating voltage with an order of magnitude increase each of the last two decades. ${ }^{[1]}$

The break thru that made this possible was the elliptical cavity, which reduced "multipacting", resonant electron loading of cavities that plagued HEPL. ${ }^{[2]}$ Fig. 2 shows how cell shapes are being optimized for specific applications. A) is the original $1989 \mathrm{CEBAF} /$ Cornell shape; B) is optimized to minimize the peak electric field in order to reduce field emission, C) is optimized to minimize the peak magnetic field in order to reduce refrigeration losses. If field emission can completely be eliminated, the latter also would provide the highest accelerating gradient.
$\mathrm{T}$

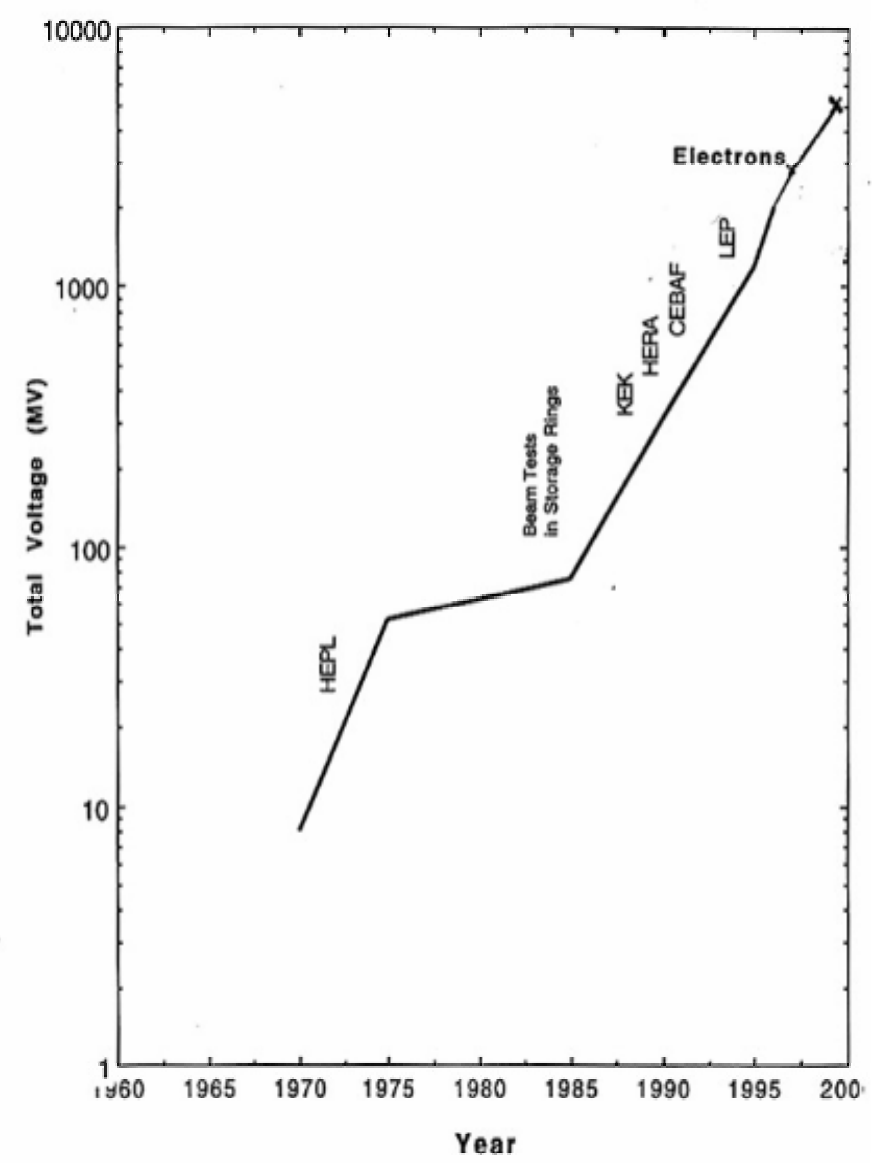

Fig. 1. Growth of accelerating voltage.
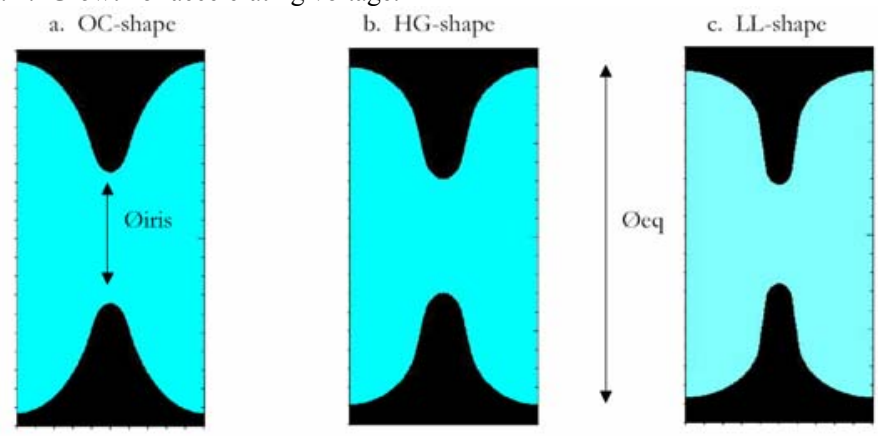

Fig. 2 Three inner cell dumbbells

\section{MAJOR SRF PROJECTS}

Manuscript received October 5, 2004. This work was suppo
Department of Energy under contract \#DE-ACO-584ER40150.

Claus H. Rode is with the Thomas Jefferson National Accelerator Facility (Jefferson Lab), Newport News, VA 23606 USA (phone: 757-269-7511; fax: 757-269-7363; e-mail: rode@jlab.org).

\section{A.CEBAF@JLab}

In 1989, construction started on a SRF re-circulating linac, 
building on the Cornell effort. CEBAF was originally designed as a $\mathrm{Cu}$ water-cooled accelerator, but switched before construction started. It uses 338 cavities at $1500 \mathrm{MHz}$ in a five turn re-circulating linac. ${ }^{[3]}$ The cavities are housed eight to a cryomodule (CM) Each CM has quick disconnects that permit it to exchange at liquid He temperatures.

The gradient specification was $5.0 \mathrm{MV} / \mathrm{m} @ \mathrm{Q}_{0}=2.4 * 10^{9}$; it achieved 7.2 MV/m.

In 1996, JLab started construction of a second much smaller accelerator, the JLab FEL, Fig. 3. In its initial configuration, it used $1 / 4 \mathrm{CM}$ for the injector and one for the linac. Two additional CMs have been added to the linac to raise its energy to $160 \mathrm{MeV}$. Over the last eight years it has increased the world FEL records by more than 3 orders of magnitude up to $8.5 \mathrm{~kW}$ average power at 6 microns. ${ }^{[4]}$

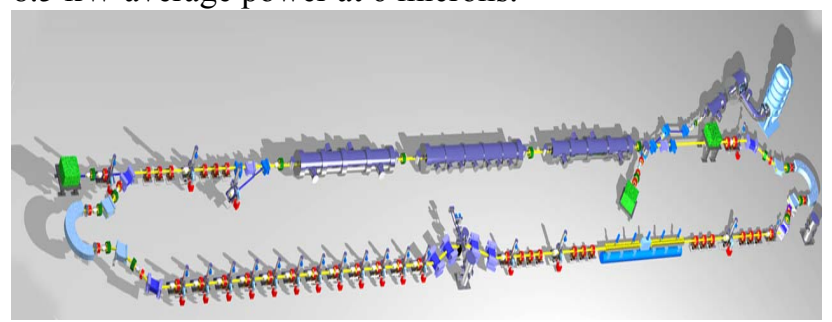

Fig. 3. JLab $10 \mathrm{~kW}$ IR FEL upgrade

We are continuing to increase performance an order of magnitude every 3 to 4 years. The current specifications are:

a) $10 \mathrm{~kW}$ average, 1 to 14 microns

b) $3 \mathrm{~kW}$ average, 0.3 to 1 microns

c) $100 \mathrm{w}$ broadband 2 to $50 \mathrm{~cm}^{-1}$

\section{B.LEPII@CERN}

In 1989, LEP, the water-cooled $\mathrm{Cu}$ electron-positron collider was commissioned. At the same time, superconducting cavity installation started, which eventually led to LEP II. The initial plan was to supplement the accelerating voltage, but by 2000, when it shut down for LHC installation, all of the $\mathrm{Cu}$ cavities had been removed to make room for the much more powerful SC cavities.

LEP II used four-cell $350 \mathrm{MHz}$ SRF cavities; four to the CM. Over the 12 years, the upgrade reached $208 \mathrm{GeV}$ in the center of mass. The total accelerating voltage was $3,600 \mathrm{MV}$ at $4 \mathrm{~mA}(465 \mathrm{~m}$ at $7.7 \mathrm{MV} / \mathrm{m}){ }^{[5]}$

\section{TESLA, TTF, VUV-FEL, \&X-FEL@DESY}

In 1990, DESY started an international effort to design a $\mathrm{TeV}$ superconducting linear collider. The first meeting was held in July-90 at Cornell in conjunction with the bi-annual SRF workshop. A TDR was produced in Mar-01. ${ }^{[6]}$

As part of this program, a beam test facility was constructed, TESLA Test Facility (TTF). In 1998, it accelerated electrons with a $100 \mathrm{MeV}$ CM. This facility has continued to grow over the last decade and is becoming an important research tool renamed VUV-FEL. Currently it is being recommissioned for $30 \mathrm{~nm}$ FEL ops with 5 CMs. In
2006, a $6^{\text {th }} \mathrm{CM}$ will be added to upgrade to $6 \mathrm{~nm}$ operation $(1 \mathrm{GeV})$.

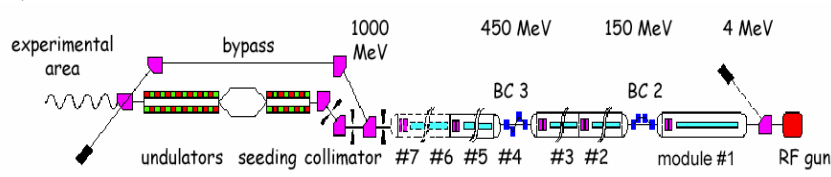

Fig. 4. VUV-FEL

These efforts have lead to the approval of the European XFEL. ${ }^{[7]}$ This is a $3 \mathrm{~km}$ long $\sim 1000$ cavity $17.5 \mathrm{GeV}$ electron accelerator.

\section{D.SNS@ORNL}

SNS, similar to CEBAF and LEP, also started as a watercooled $\mathrm{Cu}$ linac, which in 2000 switched to SRF, six months after CD\#3 (construction start). The linac produces $1 \mathrm{msec}$ $1.0 \mathrm{GeV}$ pulses to produce $1 \mathrm{MW}$ of neutrons. JLab was asked to join as the sixth member of the national lab collaboration and provide the cryogenics and $\mathrm{CMs} .{ }^{[8]}$

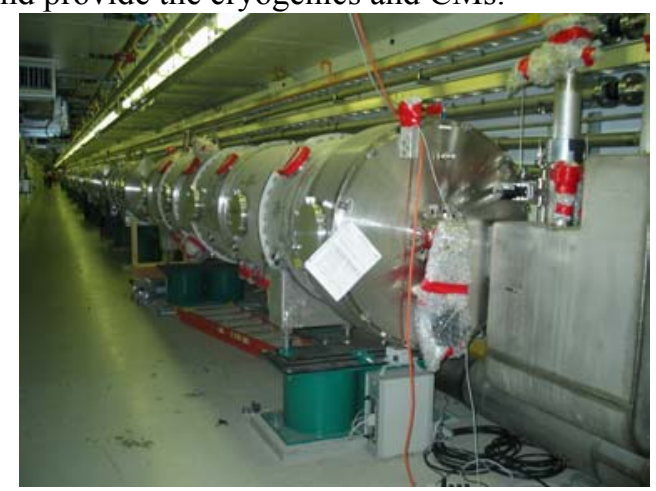

Fig. 5. SNS Linac

The protons are accelerated to $186 \mathrm{MeV}$ using a RFQ, a six tank DTL, and a four tank CCL. The SRF starts with $11 \mathrm{CMs}$ each with three $10.2 \mathrm{MV} / \mathrm{m}$ Beta $=0.61$ cavities. This is followed by $12 \mathrm{CMs}$ each with four $15.6 \mathrm{MV} / \mathrm{m}$ Beta $=0.81$ cavities. The design permits adding of nine additional Beta $=0.81 \mathrm{CM}$ to increase the linac energy to $1.4 \mathrm{MeV}$ and neutron power to 2-4 MW.

\section{DOE 20 YEAR PLAN}

In 2003, DOE's Office of Science started to develop a new 20 -year plan for future facilities ${ }^{9}$. The previous plan, known as the "Trivelpiece Plan", ended with the construction of the SNS.

Approximately 80 proposals were evaluated for "science merit" as well as "readiness" for construction. Twenty-eight projects made the list, which was broken into 12 near-term, 8 mid-term, and 8 far-term, Fig. 6. 


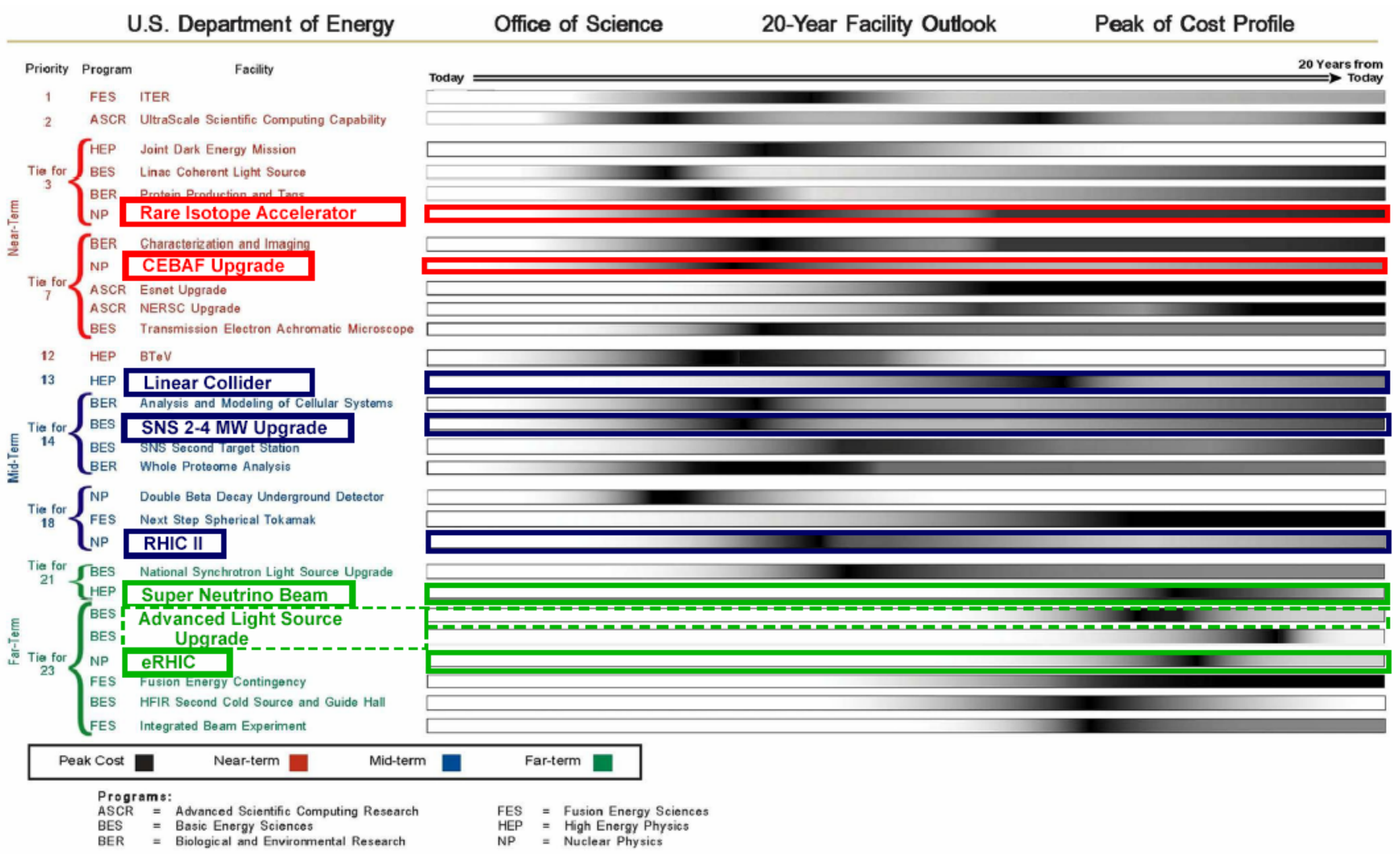

Fig. 6. 20-year Facility

A minimum of 7 out of these 28 projects require SRF technology. Including two in the near-term, both of which have been given the go to start design $(\mathrm{CD \# 0})$.

\section{A. Rare Isotope Accelerator}

In a four-way tie for third place is the Rare Isotope Accelerator (RIA).

This fully SRF facility will accelerate ions up thru Uranium with a minimum $400 \mathrm{MeV} / \mathrm{u}$ with a beam power of $100 \mathrm{~kW}$ $\mathrm{CW}$ upgradeable to $400 \mathrm{~kW}$. Protons are specified to reach $1.0 \mathrm{GeV}$.

Two different designs are being proposed by Argonne National Lab and Michigan State University. For Uranium, one first accelerates two charge states $(\mathrm{q}=28 \& 29)$ to $\sim 10$ $\mathrm{MeV} / \mathrm{u}$ and the first stripper. Five charge states ( $\mathrm{q}=\sim 70$ to 75 ) are then accelerated to $\sim 80 \mathrm{MeV} / \mathrm{u}$ and the second stripper. Four charge states ( $\mathrm{q}=87$ to 90 ) of an almost fully stripped beam are then accelerated to $400 \mathrm{MeV} / \mathrm{u}$.

Due to the fact that this is an ion accelerator, both designs require about 8 different Betas. The cavity types being proposed include: Fork, Quarter Wave, Half Wave, Multi Spoke, and Elliptical.

\section{B. CEBAF $12 \mathrm{GeV}$ Upgrade}

In a five-way tie for seventh place is the CEBAF $12 \mathrm{GeV}$ upgrade. Similar to SNS, the existing facility only fills 20 of the $25 \mathrm{CM}$ slots in each linac. By installing five new CMs each four times more powerful than the original $\mathrm{CM}$, we are able to double the energy (three times the original $4 \mathrm{GeV}$ specification).

\section{Linear Collider}

Heading the mid-term list in $13^{\text {th }}$ place is the Linear Collider. This is an electron - positron collider with a length of about $25 \mathrm{~km}$. The International Technology Recommendation Panel (IRTP) just completed its review of the warm and cold technologies and unanimously recommended the SRF option.

This would be a $\mathrm{TeV}$ in the center of mass using about 20,000 cavities.

\section{Other Projects}

The two other mid-term project are upgrades of 1) the SNS, which adds nine CMs in empty slots similar to CEBAF, and 2) the RHIC, which uses e-beam cooling to improve luminosity.

In the far-term is the Super Neutrino Beam; one candidate is the Fermilab $8 \mathrm{GeV}$ proton SRF linac. Another project is RHIC converted into an electron - ion collider; where the ebeam is provided by an SRF linac.

\section{CONCLUSION}

With the large number of SRF projects worldwide, in the near future there three major challenges that face us:

\section{1) We need to train an increased workforce}

Without the Linear Collider, we need to at least double the number of SRF experts. With it tripling them, they will not be 
adequate.

2) For pulsed Accelerators, we need to improve gradients

Over the last 15 years, gradients have improved from specifications of $5.0 \mathrm{MV} / \mathrm{m}$ to goals of $35-45 \mathrm{MV} / \mathrm{m}$

3) For CW Accelerators, we need to improve Quality Factor

Over the last 15 years, $Q_{0}$ have improved from specifications of $2.4 * 10^{9} @ 5 \mathrm{MV} / \mathrm{m}$ to goals of $1 * 10^{10} @$ $20 \mathrm{MV} / \mathrm{m}$. Without this improvement, the refrigeration costs are prohibitive.

\section{REFERENCES}

[1] H. Padamsee, RF Superconductivity - 2004 Science, Technology and Applications, Ithaca, NY, 2004, pg. 9.

[2] C. Westfall, The Prehistory of Jefferson Lab's SRF Accelerating Cavities, 1962 to 1985, Newport News, VA, 1997, pg. 25.

[3] H. Grunder, The Continuous Electron Beam Accelerator Facility Project Status \& Physics Outlook, CEBAF-PR-89-030, Jefferson Lab, Newport News, VA, 1988.

[4] S. Benson, D. Douglas, M. Shinn, K. Beard, C. Behre G. Biallas, J. Boyce, H. F. Dylla, R. Evans, A. Grippo, J. Gubeli, D. Hardy, C. Hernandez-Garcia, K. Jordan, L. Merminga, G. R. Neil, J. Preble, T. Siggins, R. Walker, G.P. Williams, B. Yunn, S. Zhang, H. Toyokawa, "High Power Lasing in the IR Upgrade FEL at Jefferson Lab", Jefferson Lab, Newport News, VA, [Online Proceedings from the FEL2004]. Available:

http://fel2004.elettra.trieste.it/pls/fel2004/Proceedings. html

[5] P. Brown, O. Brunner, A. Butterworth, E. Ciapala, H. Frischholz, G. Geschonke, E. Peschardt, J. Sladen, "Performance of the LEP200 Superconducting RF System" in Proc. from the $9^{\text {th }}$ Workshop on RF Superconductivity, Santa Fe, NM, 1999, Vol I, pg. 15.

[6] Edited by F. Richard, TESLA Technical Design Report 2001-011 (CD \& http://tesla.desy.de/), Hamburg, Germany, March, 2001.

[7] E.L. Saldin, E.A. Schneidmiller and M.V. Yurkov, Deutsches Elektronen-Synchrotron (DESY), Hamburg, Germany, "Scheme For Generation of Single 100 GW 300-AS Pulse in the X-Ray SASE FEL with the use of a Few Cycles Optical Pulse from Ti-Sapphire Laser System"

[Online Proceedings from the FEL2004].Available: http://fel2004.elettra.trieste.it/pls/fel2004/Proceedings. $\underline{\mathrm{html}}$

[8] J. Preble, I. E. Campisi, E. Daly, G. K. Davis, J. R. Delayen, M. Drury, C. Grenoble, J.Hogan, L. King, P. Kneisel, J. Mammosser, T. Powers, M. Stirbet, H. Wang, T. Whitlatch, M. Wiseman, "SNS Cryomodule Performance" in Proc. from the 2003 Particle
Accelerator Conference, Portland, OR, May 12-16, 2004.

[9] Facilities for the Future of Science, A Twenty-Year Outlook, DOE Office of Science, Washington, DC, pg. 13. 